\title{
Research Paper: The Multiple Relationships Between Anxiety Sensitivity, Social Support, Perception of Pain and Life Expectancy Variables
}

\author{
Zohreh Latifi $^{*}$ (D), Mahnoosh Kiani² \\ 1. Department of Psychology, Payame Noor University, Tehran, Iran \\ 2. Department of Psychology, Isfahan (Khorasgan) Branch, Islamic Azad University, Isfahan, Iran.
}

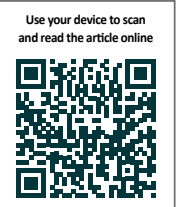

Cittation Latifi Z, Kiani M. The Multiple Relationships Between Anxiety Sensitivity, Social Support, Perception of Pain and Life Expectancy Variables. Journal of Research \& Health. 2021; 11(2):87-94. http://dx.doi.org/10.32598/JRH.11.2.1598.3

doi: http://dx.doi.org/10.32598/JRH.11.2.1598.3

\section{(c) (i) (8)}

Article info:

Received: 11 Jun 2019

Accepted: 04 Jan 2020

Publish: 01 Apr 2021

\section{Keywords:}

Anxiety, Social support, Pain perception, Life expectancy, Aging

\section{A B S T RACT}

Background: The aim of this correlational study was to investigate the multiple relationships between anxiety sensitivity, social support, and perception of pain with life expectancy.

Methods: The statistical population consisted of all older adults in Isfahan (males and females) in spring 2016, of whom 250 individuals were selected by convenience sampling method from different places. In order to measure the variables, Hope Based on Islamic Sources, Perceived Social Support, Anxiety Sensitivity, and the Perception of Pain questionnaires were used. Data analysis was conducted by Pearson correlation and simultaneous multiple regression analysis.

Results: The results indicated that there was a significant positive relationship between anxiety sensitivity, social support, and the perception of pain with life expectancy $(\mathrm{P}<0.01)$.

Conclusion: This result implies that social protection enhancement, not only increases hope but also affects the fear of one's anxiety observed by others, the perception of pain, and the fear of lack of cognitive control.

\section{Introduction}

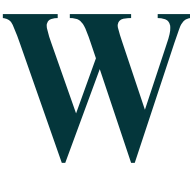

ith the annual increase in life expectancy and decreasing fertility, there will be a growth in the number of older adults in all countries, especially developing countries, such as Iran [1]. In the last census of 2004, 10\% of the world's population i.e. 606 million people, were 60 years older, but it is expected that this figure exceeds one billion and one hundred million people by 2025 . The number of people aged 60 years and older is expected to double in the next 40 years that $52 \%$ of them will be in Asia and $40 \%$ in developed countries [2]. In many developed countries, many social and therapeutic institutions have focused on the health and well-being of elderly people who need maximum health care, due to multiple problems, including mental health issues, physical disabilities, and chronic diseases [3]. Given the fact that the aging process is multi-dimensional and with various symptoms, including physical, psychological, and social, some of its aspects continually evolve and expand, while its other aspects experi-

\footnotetext{
"Corresponding Author:

Zohreh Latifi, PhD.

Address: Department of Psychology, Payame Noor University, Tehran, Iran.

Phone: +98 (913) 1139781

E-mail: z_yalatif@yahoo.com
} 
ence a decline [4]. One of the positive factors affecting healthy and productive lives is hopefulness. Some researchers believe that the concept of hope is related to faith, adjustment, and capability which can make current negative situations tolerable; thus, it can be considered as an effective response to stressors [5]. Both Snyder's hope theory and hope definition emphasize cognitions constructed based on purposeful goals.

Hope can be defined as purposeful thoughts, where people use strategic thinking (perceived ability to achieve the desired objectives) and agency thinking (needed motivation for using the ways) [6]. Hope as a factor for the enrichment of life decreases people's suffering by enabling them to have a wider perspective. Ben-Ari et al. found a mediating role for hope in the relationship between psychological problems and quality of life; those who are more hopeful experience less distress and better quality of life [7].

Besides the definition of life expectancy, the importance of this construct becomes evident by referring to the results of studies that have shown its salient relationship with different variables, such as happiness [8], quality of life [9], life satisfaction [10, 11], anxiety, and depression $[12,13]$.

Anxiety is an unpleasant emotional state, in which an individual expects a bad accident to happen, but he/she is not aware of its cause [14]. As a cognitive variable, anxiety sensitivity refers to individual differences in fear of bodily sensations related to anxiety, which encompasses respiratory irritation, dizziness, and palpitations [15].

Anxiety sensitivity also refers to the fear of bodily sensations that are caused by anxiety, in which the person anticipates bodily, psychological, or social consequences [16]. The hierarchical model of anxiety [17] and anxiety expectancy theory [18], have provided further clarification in this regard. There is a significant relationship between the components of pain perception [19] and social anxiety [20] in regard to anxiety sensitivity. Social support plays an important role in stress management and the lack of social support can cause difficulty in controlling stress and adjustment for the elderly [21].

The most common definition of social support stresses the availability and quality of communication with the people who provide support resources when needed. The provision of informational, educational, and instrumental supports by society can also play an important role in the positive feelings of elderly people towards life [22].
Perceived social support has a great impact on physical and mental health, life satisfaction, and different aspects of quality of life, and it is known as an effective moderating factor contributing to coping and adaptation to stressful life situations [23]. Social protection has been classified into two types: 1. Received social support and 2. Perceived social support. In received social support, the emphasis is on the level of supports received by the people [24]. Perceived social support pertains to individual appraisals of the availability of support in an emergency situation [25].

Theoreticians of this field believe that the person's relationships with others are not considered as social protection unless the individual evaluates them as an appropriate and available source to meet his needs. Social support is significantly associated with life satisfaction [26] and mental health [27]. Although behavioral and psychological factors may not play a salient role in the onset of pain, these factors play a decisive role in the continuing pain and the resulted disability [28].

Pain is an unpleasant sensory and emotional experience associated with tissue damage. On the other hand, pain sensation like other senses is vital to human functions and survival, but when its severity or duration goes beyond certain limits this leads to emotional confusion, disability, and dysfunction, which in turn could lead to heavy costs for individuals and society [29]. Therefore, interest in the study of the effects of the pain psychological aspects on the perception of the pain and patients' lives has been growing in recent decades [30]. Components of stress [31], cognitive and emotional factors [32], and self-efficacy [33] have shown a relationship with each other with respect to pain. Compared with different periods of life, old age is a period where health and wellbeing are of vital importance [34]

Given the paucity of studies examining the role of hopefulness in mental health problems, especially in the final stages of life, there is a need to examine effective factors on hope in this vulnerable group. Accordingly, the main purpose of the current study was to determine the multiple relationships between anxiety sensitivity, pain perception, social support, and life expectancy in the elderly aged 60 to 104 years.

\section{Methods}

This statistical population of this correlational research consisted of all elderly people in Isfahan (males and females) in spring 2016, of whom 250 individuals were selected by convenience sampling method from differ- 
ent places (investigators made a great deal of effort to carry out random sampling method but due to sensitive situation of the elderly and lack of proper cooperation, finally sampling was conducted by convenience sampling method in different places). The sample size was determined using the Kerlinger sample size formulation $(n=200)$. To avoid attrition, the sample size was increased to 250 subjects.

The inclusion criteria were the age of 60 years or older, being able to communicate either by speaking or writing, no history of asthma, and no olfactory disorders. The exclusion criteria were no history of mental disorders, no use of herbal remedies, and no use of alternative medicine over the past week.

\section{Measuring tools}

\section{Multidimensional Scale of Perceived Social Support (MSPSS)}

Multidimensional Scale of Perceived Social Support (MSPSS) developed by Zymet et al. was used to measure perceived social support from family, friends, and significant others [35]. This scale has three subscales and 12 items: Family: items 3, 4, 8, and 11, friends: items 6 , 7, 9, and 12, and significant others: items 1, 2, 5, and 10. The items are scored on a 7-point Likert scale from 1: strongly disagree to 7: strongly agree. Subscale scores are computed by summing the item responses. The total score can be obtained by summing all the items from 1 to 12 and the possible total scale score ranges from 12 to 84. Higher scores indicate higher perceived social support and vice versa. The scale has been shown to have good reliability in previous studies. Researchers using a sample of 788 high school students, found an internal consistency of 0.86 to 0.90 for the subscales and .86 for the whole scale assessed by Cronbach's alpha. The alphas reported were $0.89,0.86$, and 0.82 for three dimensions of social support received from family, friends, and significant others, respectively [36].

\section{Khalilian and Shalamzari Hope Scale Based on Islamic Sources (Short Form)}

Khalilian and Shalamzari Hope Scale based on Islamic Sources (short form) consisted of 15 questions, scored on a 4-point Likert scale, and questions 12 and 13 are scored reverse. A minimum score of 15 indicates low hopefulness and a maximum score of 60 represents high hopefulness. The internal consistency of the scale by Cronbach's alpha coefficient was 0.97 [37].

\section{Pain Perception Scale}

To measure the perception of pain in this study, the pain perception scale developed by yosefi et al. adapted from McGill Pain Questionnaire was used. Thus, a 14-item scale of different pain experiences (exhausting pain, degenerative pain, electric shock, feeling frozen, thunder stroke, itching, tickling or tingling, and numbness) was developed. Each item is rated on a 5-point Likert type scale from 1 (not at all) to 5 (extremely) with the total scale score ranging from 14 to 70 . High scores indicate higher levels of pain. Five clinical specialists confirmed its face validity. Its internal consistency assessed by Cronbach's alpha was 0.90 [38].

\section{Reyes-Peterson Anxiety Sensitivity Scale (Revised)}

The 16-item Anxiety Sensitivity Scale (revised) by Reese and Peterson was used to measure the fear of anxiety symptoms. Low scores indicate that a person experiences low anxiety sensitivity and vice versa. This questionnaire was assessed by three methods of internal consistency, test-retest, and split-half reliability that the coefficients of $0.93,0.95$, and 0.97 were yielded for the whole scale, respectively. Concurrent validity was established through the simultaneous implementation of the SCL-90 questionnaire and the correlation coefficient of 0.56 was obtained. Correlation with the total score was acceptable (between 0.74 and 0.88 ). The correlation between subscales was between 0.40 and 0.68 .

In this study, the reliability coefficient of life expectancy, social support, perceived pain, and anxiety sensitivity were $0.83,0.87,0.95$, and 0.90 , respectively. Finally, data were analyzed using SPSS V. 16 software, AMOS V. 21, and statistical tests. The confidentiality of the participants' data was acknowledged and they were also assured that the results of the questionnaires will be used only for research purposes.

\section{Results}

We assessed old adults, including 144 males and 196 females with an age range of 60 to 104 years. The mean age of the sample members was 66.91 years with a standard deviation of 7.44

Initially, Pearson correlation was used to examine the relationship between life expectancy and anxiety sensitivity, social support, and pain perception and its dimensions among the older adult. The correlation coefficients are presented in Table 1 . 
Table 1. Pearson correlation coefficients of studied scales

\begin{tabular}{|c|c|c|c|c|c|c|c|c|c|c|}
\hline Row & Scale & 1 & 2 & 3 & 4 & 5 & 6 & 7 & 8 & 9 \\
\hline 1 & Hope & 1 & & & & & & & & \\
\hline 2 & Pain perception & -0.06 & 1 & & & & & & & \\
\hline 3 & Sensitivity & -0.04 & $0.52^{* *}$ & 1 & & & & & & \\
\hline 4 & Somatic concerns & -0.03 & $0.60^{* *}$ & $0.96^{* *}$ & 1 & & & & & \\
\hline 5 & Cognitive control & $-0.14^{*}$ & $0.21^{* *}$ & $0.79^{* *}$ & $0.63^{* *}$ & 1 & & & & \\
\hline 6 & Anxiety & 0.07 & $0.42^{* *}$ & $0.86^{* *}$ & $0.77^{* *}$ & $0.60^{* *}$ & 1 & & & \\
\hline 7 & Support & $0.31^{* *}$ & $-0.10^{*}$ & $-0.25^{* *}$ & $0.22^{* *}$ & $-0.32^{* *}$ & $-0.16^{* *}$ & 1 & & \\
\hline 8 & Family & $0.33^{* *}$ & $-0.33^{* *}$ & $-0.36^{* *}$ & $0.36^{* *}$ & $-0.32^{* *}$ & $-0.26^{* *}$ & $0.82^{* *}$ & 1 & \\
\hline 9 & Friends & $0.13^{* *}$ & $0.10^{*}$ & $-0.13^{* *}$ & $0.09^{* *}$ & $-0.21^{* *}$ & -0.07 & $0.75^{* *}$ & $0.44^{* *}$ & 1 \\
\hline 10 & Significant others & $0.30^{* *}$ & -0.04 & $-0.15^{* *}$ & $0.10^{* *}$ & $-0.24^{* *}$ & -0.08 & $0.86^{* *}$ & $0.57^{* *}$ & $0.45^{* *}$ \\
\hline
\end{tabular}

${ }^{* *} \mathrm{P}>0.01 ;{ }^{*} \mathrm{P}>0.05$.

IMPA

Life expectancy only had a significant positive relationship with social support and dimensions of family, friends, and important others at $\mathrm{P}>0.01$. This means that the higher the level of social support and its dimensions, the higher the level of life expectancy in the elderly and vice versa. Fear of not having cognitive control had a significant negative relationship with life expectancy at $\mathrm{P}>0.05$. This means that the higher the level of having no cognitive control, the lower the level of life expectancy and vice versa. Pain perception, anxiety sensitivity, fear of physical anxiety, and fear of anxiety being watched, were not significantly correlated with life expectancy $(\mathrm{P}>0.05)$. Pain perception in the elderly had a significant positive correlation with anxiety sensitivity and its dimensions and a negative correlation with social support and its dimensions $(\mathrm{P}>0.05)$. The elderly who had a higher level of anxiety sensitivity and lower social support had a higher level of pain perception.
Also, anxiety sensitivity had a significant negative relationship with social support $(\mathrm{P}>0.01)$. This means that the lower the level of social support, the greater the anxiety of the older adult, and vice versa. Multiple regression was used to investigate the contribution of pain perception, anxiety sensitivity, and social support and their dimensions to life expectancy. In this model, life expectancy was used as a criterion variable, and perception of pain, anxiety sensitivity, social support, and its dimensions were used as prediction variables. Table 2 presents the multiple regression analysis for life expectancy prediction.

As shown in Table 2, prediction variables of social support, family, fear of lack of cognitive control, and fear of being observed by others can predict life expectancy, with standardized $\beta$ coefficients of $0.32,0.27,-0.19$, and 0.29 , respectively $(\mathrm{P}<0.01)$. However, the pain perception

Table 2. Regression coefficients for the prediction of variables affecting life expectancy

\begin{tabular}{|c|c|c|c|c|c|}
\hline Sources & B & Standardized Error & Standardized $\boldsymbol{\beta}$ & $\mathbf{t}$ & Sig. \\
\hline Constant & 41.66 & 2.07 & - & 20.06 & 0.01 \\
\hline Social support & 0.13 & 0.02 & 0.32 & 6.10 & 0.01 \\
\hline Family & 0.27 & 0.07 & 0.27 & 3.82 & 0.01 \\
\hline Fear of lack of cognitive control & -0.34 & 0.12 & 0.19 & -2.74 & 0.01 \\
\hline Fear of one's anxiety being observed by others & 0.55 & 0.15 & 0.29 & 3.64 & 0.01 \\
\hline Pain & -0.03 & 0.02 & 0.07 & -1.19 & 0.23 \\
\hline
\end{tabular}


Table 3. Multiple regression model for predicting life expectancy

\begin{tabular}{ccccccccc}
\hline $\begin{array}{c}\text { Membership in Social } \\
\text { Network }\end{array}$ & Sum of Squares & $\mathbf{d f}$ & Mean of Squares & $\mathbf{F}$ & Sig. & $\mathbf{R}$ & Adjusted R $^{2}$ & Estimation Error \\
\hline Regression & 1732.59 & 7 & 278.94 & 11.17 & 0.01 & 0.43 & 0.17 & 5.29 \\
Residual & 8557.98 & 328 & 34.61 & & & & & \\
Total & 11009.98 & 335 & & & & & & \\
\hline
\end{tabular}

URA

failed to significantly predict the life expectancy scale $(\mathrm{P}<0.01)$. The results of the multiple regression models for life expectancy prediction are presented in Table 3.

As shown in Table 3, the model of life expectancy prediction by anxiety sensitivity, social support, and its dimensions was significant at the level of $\mathrm{P}<0.01\left(\mathrm{R}^{2}=0.17\right.$, $\mathrm{F}=11.17$ ). According to the adjusted coefficient of determination, $17 \%$ of life expectancy scores were influenced by anxiety sensitivity and social support.

\section{Discussion}

The obtained results showed that life expectancy has a significant and positive relationship with social support and its dimensions of family, friends, and significant others. Based on this model, the higher the level of social support and its dimensions, including family, friends, and significant others, the higher the level of life expectancy of the older adult and vice versa. This finding is in line with the results of Dai \& Heine $[39,40]$.

Concerning anxiety sensitivity, the fear of lack of cognitive control subscale was negatively correlated with life expectancy. This finding is in line with other reports [11$15,19,20,27]$. Also, there was a positive and significant relationship between pain sensation and social support and its dimensions, whereas it had a negative and significant relationship with social support and its dimensions. These findings were in line with other findings [26-28].

Pain sensation, anxiety sensitivity, the fear of bodily sensations, and the fear of one's anxiety for being observed by others showed a significant relationship with life expectancy. These findings are in line with the findings reported by Sharif et al. [9], Rezaie-Shahsavarloo et al. [10], and Sheykhi et al. [11].

Because aging is a multidimensional process and affects different aspects of the individual's life, including the biological, psychological, relationships, and social aspects, all factors affecting these dimensions can influence this process, which these multiple dimensions were also considered in this study. Regarding the biological dimension, we examined the perception of pain that shows how one evaluates the extent of pain regardless of its actual extent. Concerning the psychological dimension, we considered anxiety sensitivity. Simply, anxiety sensitivity is how an elderly person interprets and evaluates his or her arousal and physical sensations, which are not necessarily desirable. This evaluation can definitely influence their management and reactions to these.

On the other hand, the social dimension of social support has been the focus of researchers. Social support includes the feeling of availability of the close and supportive people (family, friends, and even educational and welfare facilities) when needed, which includes received and perceived support. This is mainly a psychosocial feeling, and ultimately, there are multiple relationships between these factors and hope that has a strong relationship with the degree of ability and self-improvement motivation, problem-solving, coping effectively with stressful conditions, and quality of life, that underlie relaxation. When the person does not feel alone, he or she will not become helpless or incapable and when there is no feeling of helplessness, he/she makes every effort to maintain his or her self-esteem, capability, and health to cope with minor pain and stress. When friends and family are available, people try to maintain and continue their good relationships.

In conceptualizing these findings, it could be said that social support and kindness from friends, family, and significant others can activate the calmness and security system in this group and deactivate tension and defensive system. Anxiety sensitivity in old age becomes more salient when we consider the fact that physiological, psychological, and emotional changes are inevitable in this period. Many people fear the aging process or even hate it.

Older adults with serious weaknesses are an unpleasant reminder of how we will ultimately be faced with these weaknesses, such as walking without balance, poor eyesight, loss of taste, and more susceptibility to physical diseases. 
The elderly population of Iran is increasing and old people have more physical and social problems than the other groups. Inabilities and physical health problems, neurological deficiencies, loss of loved ones, cumulative effects of many bitter experiences, stresses, and failures in medical treatments can result in hopelessness in old people. Besides cognitive disorders, anxiety disorders are among the most prevalent mental health problems that usually occur in the final stages of life. Exposure of the elderly to anger and guilt feelings and their relationship with family members are hypothesized to be the cause of this anxiety, while all of these factors can influence life expectancy.

\section{Conclusion}

It can be concluded that life expectancy was effective on one of the anxiety sensitivity scales. Life expectancy has also been effective on social support and vice versa, and social support was effective on pain sensation and anxiety sensitivity.

A limitation of the study was that the public organizations demonstrated little cooperation, which led to limited access to retired association member's data. Another limitation was a climate of distrust among the participants toward the study in producing fruitful results. Albeit, we tried to address this problem by offering reassurance to them and emphasizing the importance of their participation.

\section{Ethical Considerations}

\section{Compliance with ethical guidelines}

This study was approved by the Ethics Committee of the Payame Noor University, Tehran (Code: 03/2096).

\section{Funding}

This research was supported by the Payame Noor University, Tehran.

\section{Authors' contributions}

Study design: Both authors; Data collection and analysis: Mahnoosh Kiani; Manuscript preparation: Zohreh Latifi.

\section{Conflict of interest}

The authors declared no conflict of interest.

\section{References}

[1] Sadeghian-Motavali Z, Abedi HA, Davaridolatabadi E. Self-medication and its effective modifiable factors among elderly referred health care centers in Shahr-e-Kord in 2015. Electron Physician 2016; 8(11):3205-13. [DOI:10.19082/3205] [PMID] [PMCID]

[2] Sohrabi M, Abedanzade R, Shetab Boushehri N, Parsaei S, Jahanbakhsh $\mathrm{H}$. [The relationship between psychological well-being and mental toughness among elders: Mediator role of physical activity (Persian)]. Salmand: Iran J Ageing. 2017; 11(4):538-49. [DOI:10.21859/sija-1104538]

[3] Abbasi M, Mirderikvand F, Adavi H, Hojati M. [The relationship between personality traits (neuroticism and extraversion) and selfefficacy with aging depression (Persian)]. Salmand: Iran J Ageing. 2018; 12(4):458-66. [DOI:10.21859/sija.12.4.458]

[4] Yarian S, Rahian H, Asgharnejadfarid A, Vahedi H, Ameri NF, Dehghan Najmabadi M. [Effectiveness of ontological security training on psychological safety and existential anxiety of elder people (Persian)]. J Geontol. 2019; 3(4):1-10. [DOI:10.29252/joge.3.4.1]

[5] Ebrahimi B, Hosseini M, Rashedi V. [The relationship between social support and death anxiety among the elderly (Persian)]. Elder Health J. 2018; 4(2):37-42. http:/ / ehj.ssu.ac.ir/article-1-133-en.htm

[6] MacPherson H, Tilbrook H, Richmond S, Woodman J, Ballard K, Atkin $\mathrm{K}$, et al. Alexander technique lessons or acupuncture sessions for persons with chronic neck pain: A randomized trial. Ann Intern Med. 2015; 163(9):653-62. [DOI:10.7326/M15-0667] [PMID]

[7] Rigikouteh B, Yazdkhasti F, Etemadifar M. [The effectiveness of Dohsa-hou psychological rehabilitation program on severity of fatigue, depression, anxiety, stress and improve the quality of life in subjects with Multiple Sclerosis (MS) (Persian)]. J Research in Rehabil Sci. 2013; 9(3):445-58. https:/ / www.sid.ir/en/journal/ ViewPaper.aspx?id=377485

[8] Jamalzade R, Golzari M. [The effectiveness of hope therapy on increasing happiness and life satisfaction among elderly women residing in nursing home of Borujen (Persian)]. Salmand: Iran J Ageing. 2014; 5(18):31-48. https://www.sid.ir/en/Journal/ViewPaper.aspx?ID=465793

[9] Sharif F, Jahanbin I, Amirsadat A, Hosseini Moghadam M. Effectiveness of life review therapy on quality of life in the late life at day care centers of Shiraz, Iran: A randomized controlled trial. Int J Community Based Nurs Midwifery. 2018; 6(2):136-45. [PMID] [PMCID]

[10] Rezaie Shahsavarloo Z, Lotfi M, Taghadosi M, Mousavi M, Yousefi Z, Amirkhosravi N. Relationship between components of Spiritual well-being with hope and life satisfaction in elderly cancer patients in Kashan. J Geriatr Nurs. 2015; 1(2):43-54. http://jgn. medilam.ac.ir/browse.php?a_id=76\&sid=1\&slc_lang=en

[11] Sheykhi A, Navidian A, Keykha R, Rezaee N. [Effect of reminiscence on the happiness the retired elderly members of the Islamic Republic of Iran Army (Persian)]. Iran J Nurs. 2019; 32(119):1-11. [DOI:10.29252/ijn.32.119.1]

[12] Rahimipour M, Shahgholian N, Yazdani M. [Effect of hope therapy on depression, anxiety, and stress among the patients undergoing hemodialysis (Persian)]. Iran J Nurs Midwifery Res. 2015; 20(6):694-9. [DOI:10.4103/1735-9066.170007] [PMID] [PMCID]

[13] Aghajani M, Afaze M, Morasai F. [The effect of spirituality counseling on anxiety and depression in hemodialysis patients (Persian)]. Evidence Based Care. 2014; 3(4):19-28. https:/ / www.sid.ir/ fa/journal/ViewPaper.aspx?id=240638 
[14] Shirazi M, Koohkan Azim H, Khosravani E. [Effectiveness of psychological rehabilitation, using Dohsa-Hou, on hemodialysis patients' depression, anxiety, and stress in Zahdan city (Persian)]. J Birjand Uni Med Sci. 2016; 23(2):130-40. http:/ /journal.bums.ac.ir/ article-1-2045-fa.htm

[15] Sorbi MH, Rahmanian M, Sadeghi K, Ahmadi SM, Baghaeipour L, Yazdanpoor S. Comparison of the life expectancy and general health in type 2 diabetic patients with non-patients. Iran J Diabetes Obesity. 2014; 6(3):114-8. http://ijdo.ssu.ac.ir/ article-1-196-en.html

[16] Snyder CR. Handbook of HOPE: Theory, measures, and applications. Cambridge, Massachusetts: Academic Press; 2000. https://www.amazon.com/Psychology-Hope-You-Here-There/ $\mathrm{dp} / 0743254449 /$ ref=pd_sim_1?

[17] Watson D. Rethinking the mood and anxiety disorders: A quantitative hierarchical model for DSM-V. J Abnorm Psycholy. 2005 114(4):522-36. [DOI:10.1037/0021-843X.114.4.522] [PMID]

[18] Floyd M, Garfield A, Lasota MT. Anxiety sensitivity and worry. J Pers Individ Dif. 2005; 38(5):1223-9. [DOI:10.1016/j. paid.2004.08.005]

[19] Vesal M, Mollazade J, Taghavi M, Nazarinia M. [Prediction of depression based on perception of pain and quality of sleep due to pain catastrophizing in elderly patient with rheumatoid arthritis (Persian)]. J Anesthesiol Pain. 2015; 6(2):69-80. http://jap.iums. ac.ir/article-1-5206-en.htm

[20] Pine DS, Cohen P, Gurley D, Brook J, Ma Y. The risk for earlyadulthood anxiety and depressive disorders in adolescents with anxiety and depressive disorders. Arch Gen Psychiatry. 1998; 55(1):56-64. [DOI:10.1001/archpsyc.55.1.56] [PMID]

[21] Azman A, Jamir Singh PS, Sulaiman J. Caregiver coping with the mentally ill: A qualitative study. J Mental Health. 2017; 26(2):98103. [DOI:10.3109/09638237.2015.1124395] [PMID]

[22] Poulin J, Deng R, Ingersoll TS, Witt H, Swaln M. Perceived family and friend support and the psychological well-being of American and Chinese elderly persons. J Cross Cultur Gerontol. 2012; 27(4):305-17. [DOI:10.1007/s10823-012-9177-y] [PMID]

[23] Conversano C, Rotondo A, Lensi E, Della Vista O, Arpone F, Reda MA. Optimism and its impact on mental and physical wellbeing. Clin Pract Epidemiol Ment Health. 2010; 14(6):25-9. [DOI:10. 2174/17450179010060100025] [PMID] [PMCID]

[24] Trepte S, Dienlin T, Reinecke L. Influence of social support received in online and offline contexts on satisfaction with social support and satisfaction with life: A longitudinal study. Media Psychol. 2015; 18(1):74-105. [DOI:10.1080/15213269.2013.838904]

[25] Szymona-Pałkowska K, Janowski K, Pedrycz A, Mucha D, Ambroży T, Siermontowski $P$, et al. Knowledge of the disease, perceived social support, and cognitive appraisals in women with urinary incontinence. Biomed Res Int. 2016; 3(6):92-7. [DOI:10.1155/2016/3694792] [PMID] [PMCID]

[26] Hosseini SH, Bahraminejad Z. The role of social support networks in public health and health service utilization among the elderly. J Res Health. 2014; 4(4):955-61. http://jrh.gmu.ac.ir/article1-285-en.html

[27] Ebrahimi Z, Esmaeilzadeh Ghandehary MR, Veisi K. Comparing the efficacy of yoga exercise and intergenerational interaction program on mental health of elderly. J Res Health. 2019; 9(5):40110. [DOI:10.29252/jrh.9.5.401]
[28] Vahedian-Shahroodi M, Moshki M, Esmaily H, Moradi Gholezo S, Lael-Monfared E, Damirchi M. Predicting the intention to perform physical activity in the elderly based on the theory of planned behavior. J Res Health. 2019; 9(4):324-9. [DOI:10.29252/jrh.9.4.324]

[29] Jensen M, Moore M, Bockow T, Ehde D, Engel J. Psychosocial factors and adjustment to chronic pain in persons with physical disabilities: A systematic review. Arch Phys Med Rehabil. 2012 92(1):146-60. [DOI:10.1016/j.apmr.2010.09.021] [PMID] [PMCID]

[30] Lumley MA, Cohen JL, Borszcz GS, Cano A, Radcliffe AM, Porter LS, et al. Pain and emotion: A biopsychosocial review of recent research. J Clin Psychol. 2011; 67(9):942-68. [DOI:10.1002/ jclp.20816] [PMID] [PMCID]

[31] Taheri M, Hasani J, Rezayi Jamalooei H, Taheri M. Attachment styles and emotional intelligence components: The predictors of health dimensions. J Res Health. 2019; 9(1):82-9. [DOI:10.29252/ jrh.9.1.82]

[32] Sajjadian I, Taher Neshat Dost H, Molavi H, Bagherian Sararoudi R. [Cognitive and emotional factors effective on chronic low back pain in women: Explanation the role of fear-avoidance believes, pain catastrophizing and anxiety (Persian)]. J Res Behav Sci. 2012; 10(5):305-16. http://rbs.mui.ac.ir/browse.php?a_code=A-10-39$117 \&$ slc_lang=fa\&sid $=1$

[33] Saariaho T, Saariaho A, Karila I, Joukamaa M. Pain Disability Scale (PDS). New York: APA Psyc Tests; 2012. [DOI:10.1037/t34792-000]

[34] Steptoe A, Deaton A, Stone AA. Subjective wellbeing, health, and ageing. Lancet. 2015; 385(9968):640-8. [DOI:10.1016/S01406736(13)61489-0] [PMID] [PMCID]

[35] Canty-Mitchell J, Zimet GD. Psychometric properties of the multidimensional scale of perceived social support in urban adolescents. Am J Community Psychol. 2000; 28(3):391-400. [DOI:10.1023/A:1005109522457] [PMID]

[36] Sohrabbeiga A, Arjomandnia AA. Investigation of relationship between perceived social support with scales of mental wellbeing, in mothers having exceptional and normal children. Int Academ J Soc Sci. 2015; 2(10):20-33. https:/ / www.semanticscholar.org/paper/Investigation-of-relationship-between-perceived-of-Sohrabbeig-Arjom/4da9414b613e0e02b11cd95b7fe1a7f96c6fa7cc

[37] Khalilian Shalamzari M, Jandaghi GH, Pasandide A. [Construction and validation of Hope Scale Based on Islamic sources (Persian)]. J Ravanshenasi-va-Din. 2013; 6(1):76-59. https://www.magiran.com/paper/1135787?lang=en

[38] Khosravi M, Sedighi S, Moradi SH, Zendedel K. PersianMcGill pain questionnaire translation, adaptation and reliability in cancer patients: A brief report. Tehran Uni Med J (TUMS). 2013; 71(1):53-8. https://tumj.tums.ac.ir/browse. php?a_id=38\&sid=1\&slc_lang=en

[39] Dai Y, Zhang CY, Zhang BQ, Li Z, Jiang C, Huang HL. Social support and the self-rated health of older people: A comparative study in Tainan Taiwan and Fuzhou Fujian province. Medicine (Baltimore). 2016; 95(24):e3881. [DOI:10.1097/MD.0000000000003881] [PMID] [PMCID]

[40] Heine C, Gong CH, Browning C. Dual sensory loss, mental health, and wellbeing of older adults living in China. Front Public Health. 2019; 7:92. [DOI:10.3389/fpubh.2019.00092] [PMID] [PMCID] 
This Page Intentionally Left Blank 